\title{
Neuro-Doping as a Means to Avert Fascistoid Ideology in Elite Sport
}

\author{
Torbjörn Tännsjö (i)
}

Received: 3 March 2020 / Accepted: 28 June 2020 /Published online: 16 July 2020

(C) The Author(s) 2020

\begin{abstract}
Assume that neuro-doping is safe and efficient. This means that the use of it, and similar future safe methods of enhancement in sport, may help those who are naturally weak to catch up with those who are naturally strong and sometimes even defeat them. The rationale behind anti-doping measures seem to presuppose that this is unfair. But the idea that those who are naturally strong should defeat those who are naturally weak rests on a fascistoid ideology that sport had better leave behind. Neuro-doping may be seen as a means to undermine the fascistoid notion of fairness. The conjecture is that, given that society adopts what will be characterized as a policy of biological egalitarianism, this will happen. Then people will compete in society in general and in sport in particular on more equal biological terms. The fascination with natural strength, and the cheering for the winners, can then go away. Instead we see a liberated sport where we take part in it for the sheer fun of doing so. Neuro-doping, and similar techniques, may be a means that helps to liberate elite sport from its perverse view of fairness.
\end{abstract}

Keywords Biological egalitarianism · Contempt for weakness $\cdot$ Fascistoid ideology $\cdot$ Free will $\cdot$ Neuro-doping

T. Tännsjö $(\bowtie)$

Department of Philosophy, Stockholm University, Stockholm, Sweden

e-mail: torbjorn.tannsjo@philosophy.su.se

\section{Introduction}

What is neuro-doping? Neuro-doping means that certain techniques aimed at brain stimulations are used, not to cure disease or to obviate disabilities, but to enhance sport performance. ${ }^{1}$ Here are the methods typically used in neuro-doping:

Two major non-invasive techniques of brain stimulations are transcranial magnetic stimulation (TMS) (Hallett, 2007; Rossi et al., 2009), and transcranial direct current stimulation (tDCS) (Stagg and Nitsche, 2011). In TMS, an electric coil held over the head applies magnetic pulses to create currents in the brain. In tDCS, a low, continuous electrical current is delivered to the brain by using surface electrodes attached on the scalp. TMS and tDCS have been used in both research and clinic (Shin and Pelled, 2017) for example to examine alterations in cognitive function or motor skills or to assist in recovering motor function after a stroke (Gomez Palacio Schjetnan et al., 2013 ) or reducing fatigue in patients with multiple sclerosis (Saiote et al., 2014). ${ }^{2}$

\footnotetext{
${ }^{1}$ From a statuary and legalistic perspective what is here defined as 'neuro-doping' is not doping, since it has not (yet) been added to WADA's list of prohibited methods.

2 [1] See this article for the references in the quoted passage. For a recent review of potential medical hazards and ergogenic effects, see [2]
} 
The idea of neuro-doping is yet mainly speculative. We still do not know what ergogenic effects it has and even if it seems to be safe, we do not know that for certain either. However, for the sake of the argument in this paper, I assume that neuro-doping is safe and carries with it a considerable ergogenic effect. What are we then to say about it? And what are we to say about similar techniques that may evolve in the future? These are the broad questions I ask in this paper. In order to answer them one has to make them both more precise and specific. I will do so now.

My argument goes like this. I first speculate about what kind of gains we can make in terms of enhanced skills by means of neuro-doping. I then turn to medicine and discuss briefly how the techniques will be adopted in that context. I am interested in the question from both an empirical (what will happen?) and a normative (what ought to happen?) point of view. The next step is to look at people at large who can use the techniques, not to have diseases cured, but for the purpose of enhancement. Again, I am interested in both the empirical and the normative question. I argue that we must acknowledge that there will be a demand for the techniques. Society and political authorities need to tend to the matter how the techniques should be handled, then. I argue that the aim of the use of them should be biological egalitarianism. Society should subsidize the use of the techniques in a manner that means that natural variations are avoided in an ambition to level up to the point where the most skilled individuals are at present.

Suppose we do that, what will the effects be in sport in general and in elite sport in particular? I discuss different scenarios and argue that the most likely one is that sport will develop in a direction inimical to elitist sport as we know it today. The fascination with the winners in elite sport today rests on what I characterize as a fascistoid fascination with natural strength which comes, I argue, with a corresponding contempt for weakness (hence the characterization of the ideology as 'fascistoid'). There will be no room for this ideology when we meet as equals in sport competitions.

Let us begin our speculation with simple and trivial possibilities. Suppose that, in a foreseeable future, methods of non-evasive and medically innocuous neurological intervention develop, helping those who are subjected to them to enhance their capacity to focus and to avoid being hampered by poor nerves when they are supposed to perform at the peak of their capacities. The result may be similar, but we speculate, superior to the use of betablockers which is widely practiced among musicians but forbidden in sport. We could also add an enhanced capability of reacting fast to visual stimuli, such as the approach of a ball, a punch, or another athlete, of importance in many sports.

What effect would this development have, within medicine, within sport and within life in general? I will address these questions.

Let us also be more fanciful and speculate along more far-fetched possibilities. Let us suppose that methods of neuro-doping evolve rendering ordinary training much more efficient and allowing athletes to improve (enhance) their motor skills in a manner that would be impossible without neuro-doping. Part of the explanation might be that they can now train harder given the effort they usually put in - to the extent that this is possible to do without harming the body. Neurodoping will help them to put in an extra effort, by both providing them with stronger motive to press themselves to the limit and by making it hurt less when they do so.

What effect would the existence of effective methods of neuro-doping have, within medicine, within sport and within life in general?

\section{The Use of NEURO-Doping in Medicine and (Soon) among People at Large}

I suppose no one would object to the use of non-invasive techniques of brain stimulation such as transcranial magnetic stimulation, and transcranial direct current stimulation, when the aim of the use is, say, to recover motor function after a stroke. If the aim is to cure a disease or help a patient suffering from a loss of a normal human function, then there will be strong support for the use of such techniques. This is so even if the disfunction is congenital. Here the subject tends to be a bit sensitive, though. ${ }^{3}$ Yet, in most cases most people, and increasingly so, will welcome these techniques also in such applications. However, to the extent that they can also help to enhance the performance of normal people there is bound the be resistance. It is not clear that this resistance is strong enough to hold up against people who want to use the techniques, though.

\footnotetext{
${ }^{3}$ Some deaf peoples' organizations have protested against the use of cochlea implants giving hearing to deaf children. The resistance seems to wither, however.
} 
If these techniques are banned from a system of tax financed health care a problem will be that those who can afford them will seek help outside the system. If the use of them is criminalized in one country, then this ban is bound to engender medical tourism. I conjecture that it will be difficult not to include these techniques in the publicly subsidized health care system. The reason is that the skills you acquire when you resort to these techniques tend to give you a competitive edge over other people. In particular this will be so in the job market. But then it will be conceived of as unfair if rich people can buy this competitive advantage, at home or overseas, while poor people will have to rest satisfied without it. In systems where health care is publicly financed it is taken for granted that children suffering from ADHD (attention deficit hyperactivity disorder) should be provided not only with special pedagogical resources at schools but also with necessary medication.

However, if through subsidies, human enhancement through brain stimulation will become a social and political issue, hence placed in the hands of political authorities, it will be necessary for society, and for politics, to shape a system where these techniques are systematically put to use. What should the aim of such a system look like? Society should be informed by the ideal of biological egalitarianism, I submit.

\section{Biological Egalitarianism}

Biological egalitarianism is the view that, biologically speaking, in all important respects human beings are equal. No matter how we conceive of the importance of various different biological aspects, this seems to me to be false. The idea behind biological egalitarianism is not that all share all skills, of course, but the idea is rather that if you lack one skill in particular, there is compensation in the fact that instead you own many other important skills. But this is certainly not always or even typically the case. However, conceived of rather as a normative than a descriptive view, biological egalitarianism has something going for it. At least it seems that we ought, if possible, to level out some biological differences in some important respects between people. This is something we should do with regard to our cognitive capacities, but also with regard to capacities which happen to be of interest, not only in society at large, but also in sport competitions, or so I will argue in this paper. The important thing is to level out those capacities granting, when people differ with regard to them, a competitive social edge.

The idea that we should level out differences between people with regard to cognitive capacities is not new. It has been proposed for example by Allen Buchanan, Dan W. Brock, Norman Daniels, and Daniel Wikler:

Suppose we had an intervention that allowed us to improve reading or math skills, perhaps through an effect on short-term memory, attention, or some other component of cognitive processing capabilities. Suppose further that its effect is more pronounced for those who perform in the lower half of the normal performance distribution, so that it reduces variance in reading ability by pulling up the bottom. Then, just as we would consider it remiss if educational institutions did not incorporate a pedagogical technique that had the same effects, we might think medical institutions should provide the intervention, costs and resources permitting [3].

I have discussed this issue in my 'Biological Egalitarianism [4]. In the present paper I will rely on my general argument in that article, but apply my argument to skills which happen to be of importance in sport and restrict myself to non-invasive methods of brain stimulation rather than gene therapy. In this paper and elsewhere [5]. I have suggested that it might be a good idea to level out our cognitive capacities. I will here belabor the more restricted use of the idea, applied to skills of importance in sport and enhanced through non-invasive methods of deep brain stimulation (or relevantly similar techniques).

The levelling out between skills giving those who possess them at relatively high levels a competitive edge is almost irresistible. It is hard to defend that, if methods of avoiding such differences exist, they should not be used. Why should those who are less skilled be condemned to lower positions in society. Why not allow them at least to compete on equal terms with other people?

One might object that it is a better tactic to make society less competitive. I have no objection to such an approach as such. I think we should make society less competitive. However, it will take a long time to achieve such a goal and hence it would be wise to use the biological egalitarian program in tandem with the social reforms that render society less competitive. It might 
even be helpful to the social project if many of the biological differences go away.

And there exists another rationale behind the biological egalitarianism besides avoiding that some people will have to end up as losers in a competitive society. I think of the simple fact that it makes people happier when they are capable of pursuing the kinds of project in life they want to pursue. Their own lack of talent should not stand in the way of their dreams of how to live their lives.

Our natural response to different skills is, it seems, as pointed out by Buchanan et al. that, if we can level them out through 'ordinary' means such as education, we would think of it as 'remiss' not to do so, and to the extent that we cannot do so we are prepared at least to some extent to compensate those who are less talented for their lack of skills. But, then, why not use any means to eliminate the differences, to the extent that this can be done in a non-evasive and safe manner? For the sake of the argument I assume that deep brain stimulation of the sort relevant to skills in sport is non-evasive, efficacious, and safe. Then, why not use it? And why not use similar techniques that may evolve in the future?

We sometimes meet with the argument that life would be dull if people were (more) similar to one another. Or, more importantly perhaps, there may be a problem with value pluralism. This is what Buchanan et al. claims in a more cautious note in the same book on the subject:

What is regarded as a natural asset as opposed to a natural deficit and which natural assets are regarded as most valuable, depend in part on what we assume to be a good human life. And that is typically much more controversial and less capable of being determined by anything like objective, universal criteria than most of us like to admit. $^{4}$

This is true if we refer to interests, careers, temperaments, and so forth. Even mood enhancement may be problematic (not all people are hedonists). However, the argument lacks forth in relation to basic capacities. Unless we take pleasure in bullying these people, it doesn't add to our communal life when some people are clumsy, have difficulties to read, have no sense of

\footnotetext{
${ }^{4}$ Ibid., p.80. It is of note that the book has four authors and the message sent is not always univocal.
}

music (lack pitch, for example), cannot distinguish between colors, are bad at adding up sums, or cannot remember codes. To the extent that people are destined to be like this we tend to feel pity for them and, in order to have them integrated in society, we are prepared to compensate for their shortcomings. But, if so, if such exist that are innocuous and non-evasive, why not through medical measures help them to an equal standing with their peers?

There may also be a problem with social environments. Again, a caution from Buchanan et al.:

Nevertheless, the fact that what counts as a resource will sometimes vary across social environments makes it misleading to talk glibly about "genetic equality". 5

However, to the extent that we focus on capacities, this variability seems to be of little importance. If we have no desire to exercise a certain capacity we need not do so, even if it has been given to us. And we should restrict our ambition to level out natural capacities to the extent that they grant people a competitive edge over others; this is how I understand the egalitarian program. Then it doesn't matter, really, if, with a certain capacity of importance in ordinary circumstances, some people happen to end up in environments where it makes no difference if they have it or not. The mere possession of this capacity, even if in the present context it is useless, should be of no harm either. It would be like having a good natural sense for spelling among illiterates. This capacity would be of no avail to you, but it would in no way harm you either. And in a more mundane setting, it is no problem to have a talent for mathematics, even if you do not pursue a career as a mathematician but invest your time and interest in music.

It is my firm normative belief that society should aim at biological egalitarianism, as here described. I am also prepared to add that I believe that here reality will follow morality. Egalitarianism will be the aim at least wellordered welfare states will go for, once it appears as a realistic option. The egalitarian basis of the welfare state will translate seamlessly into the biological program as such.

If all this is accepted we need to decide whether to level up or down. It is probably easier to level down, but

\footnotetext{
${ }^{5}$ Ibid.
} 
this is not a serious possibility. It would not be accepted by people at large, and it would bring with it costs to society because of lack of efficiency. So, the only realistic option is, if we want to level out differences, to level up.

As was alluded to by Buchanan et al. it is natural to assume that it is easier to help those who lag behind to catch up with those who are more talented, than to enhance those who are already at the top in a population. This biological fact, if it is a fact, is propitious to the idea of biological egalitarianism conceived of as the idea that we should level up. For the sake of the argument, I take for granted that Buchanan et al. are right in their assumption that those who need the services most will also be most talented at transforming them into improved capabilities, given that all have equal access to them.

\section{Compulsory or Not?}

But what are we to say about the concern that only those who are rich will avail themselves of these medical services? It is of note that this concern is based on egalitarian grounds. So, it should, as such, speak in favor of biological egalitarianism. And to avoid the result that those who are rich use the methods exclusively, a welfare state would see to it that these services are subsidized within the public health care system. This means that they are at anyone's free disposal.

What if some people who need most to seek these services for their children abstain out of ignorance or negligence? Should the program aiming at biological equality be made compulsory? Arguments could be given for and against a mandatory program. There is no need to go into them here. If the techniques are noninvasive and effective it is likely that most people will seek the services, once they are free of charge.

Note that it is possible to strike a middle ground here, in the manner Swedish authorities treat the parents who are members of Jehovah's Witnesses and who, for religious reasons, refuse life-saving blood transfusions for their children. Society (the local municipality) then takes over custody from the parents for the child, gives the transfusion, and then returns the child to the custody of the parents. This means that no compulsory treatment is practiced. The children are not treated against the will of their custodians, since society has now taken over responsibility in this regard. This might be a way for society of handling enhancement of skills that give rise to a competitive advantage.

Anyway, this is a thorny question which I now leave for another occasion.

Let us assume that most people become convinced when the suggestion is put forward that enhancement of skills relevant to life in general should be provided by the welfare state with the aim of levelling out differences; here the idea is to level up to the level where those who are most skilled already are positioned.

Where would the effective implementation of such a program for biological egalitarianism leave sport? Clearly, many of the skills we seek in life in general are useful also in a sport context.

\section{Biological Egalitarianism and the Ethos of Sport}

The notion of justice in elite sport is very different from the one we rely on in society in general, and the difference is of importance in the present context. WADA is not explicit here but it is clear, it seems to me, that the main problem WADA sees with doping is to do with enhancement allowing that those who are naturally strong will be defeated by those who are naturally weak. Hence the ban on enhancement as one among three criteria adopted:

Section 4.3 of the current Code states that a substance or method shall be considered for inclusion on the Prohibited List if WADA, in its sole discretion, determines that the substance or method meets any two of three criteria (to do with enhancement, safety, and the spirit of sport), where the most important one relates exactly to enhancement.

Medical or other scientific evidence, pharmacological effect or experience that the substance or method, alone or in combination with other substances or methods, has the potential to enhance or enhances sport performance.

A problem with this criterion is that, if taken literally, it prohibits training. We know for certain that training has the potential to enhance or enhances sport performance. This is perhaps not as outlandish as it may sound. There may have been a time where a sports hero was supposed not to train. We see no traces of, say, Odysseus training his archery, and he seems to triumph out of sheer natural skill when his arrow passes the 12 
axes. During the Trojan war he did not use his arrow, since only a coward was supposed to kill at distance, nor did he take part in the competition held to celebrate the outcome of the war, and afterwards, during his 10 yearlong voyage there are not traces of him ever practicing.

But it is not realistic to prohibit training, since it is difficult to detect whether anyone has trained and since we all train, more or less inadvertently, as we move around. No one is a complete coach potato. For a while professional training was forbidden, but even that ban had to go for pragmatic reasons. ${ }^{6}$ I suppose the idea is that if everyone trains, those who are naturally most talented will still be the winners (their superior natural skills are as it were exhibited at a higher level). A problem here, of course, is that people react differently to training. The hope must be, however, that those who are strong are also at least as good as others to reap the fruits of training.

But if training is accepted, something must have been left out in the articulation of the criterion: the idea that we must not enhance our performance through artificial means (whatever that can mean more exactly), is a way of giving sense to the criterion. And 'artificial' is here used to distinguish the means from 'natural' ones. How do we draw the line?

Here I suppose the third criterion is intended to enlighten us, with its reference to the 'spirit of sport'. Alas, this criterion is too vague to give much direction. This is how it is stated:

Box 1

The spirit of sport is the celebration of the human spirit, body and
mind, and is reflected in values we find in and through sport,
including:
Dedication and commitment
Respect for rules and laws
Respect for self and other participants
Courage
Community and solidarity
Ethics, fair play and honesty
Health
Excellence in performance
Character and education
Fun and joy
Teamwork (World Anti-Doping Agency, 2019a)

And yet, it seems to me, what sports authorities want to keep out of sport, is indeed enhancement allowing for outcomes reflecting something else than difference with

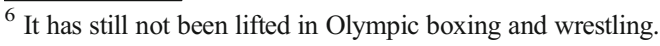

regard to natural strength. Given our natural talents, excellence in performance is what matters.

\section{Admiration for Natural Strength}

I have consistently described the notion of justice in elitist sport, based on our admiration for the winners in sport exhibiting natural superior strength, as 'fascistoid' [6]. If I am right in this claim it is of the utmost importance that we get rid of this admiration and it would be no little thing if methods of enhancement such as neurodoping (together with similar techniques we can envision in the future) would help us to do so. But am I right in my characterization of the notion of justice in sport?

Here is my rationale for this assessment of it and for my use of the term to characterize it.

The admiration for natural strength comes together with a contempt for weakness (I elaborate on this in the next section). But the admiration for natural strength and the contempt for weakness has been claimed by at least one thinker, Harald Ofstad, to be the hard core of Nazi ideology [7]. It can be questioned if this analysis is correct, perhaps there is no such thing as a hard core, or an essence, of the Nazi ideology, but the component stressed by Ofstad is definitely there (among other ones). But since it might be just one out of several strands of Nazi thought, I use the less loaded term 'fascistoid', when I speak of the sport ideology I criticize. The word is constructed in analogy with 'schizoid', allowing us to keep some distance to the 'real' thing (the schizophrenia diagnosis).

And yet, for all that, this fascination with natural strength is what renders elite sport as we know it possible. It is because we, who watch the competitions, feel this fascination, stay up at nights to find out who is best, that there is money to be invested in the business.

But can we not feel this fascination for strength without any corresponding contempt for weakness? I think not.

\section{Fascination without Contempt?}

Fascination for strength does come with contempt for weakness. This is so because the emotion (fascination) is based on an evaluative stance (those who are strong are considered better than those who are weak, that's why we cheer for them). And the evaluation works in 
the other direction as well. Those who are defeated are in a natural sense are considered worse than those who gain the upper hand. But it is impossible to judge that someone is naturally (by nature) worse than another person without feeling some sort of contempt for her. Just try to say it! 'Your biology renders you hopelessly incapable for X!' The contempt is unmistakably there. This is so on all plausible metaethical theories. According to emotivism, evaluative stances are emotions and evaluative assertions express emotions, so on emotivism this is a conceptual truth. But even on other theories it is acknowledged that there is a close connection (even if it is not a matter of identity) between evaluative judgements and emotions. Actually, even here we face a conceptual relation in the sense that we do not grant that a person has, in a practical sense of the word, 'accepted' an evaluative judgment, unless this person is emotionally committed to it [8].

The contempt need not take an aggressive form as it did among the Nazis (but obviously it can do so); and yet, some patronizing attitude is unavoidable when I make the evaluative judgement that naturally you are worse than someone else. As is seen form the example above, the mere expression of the evaluation that a certain individual is worse in nature than another one carries with it a grain of insult.

It is important to keep in mind that only evaluative comparisons are nasty in the relevant sense. You can make the strictly empirical judgement that one athlete is stronger than another and hence eligible for the team, without making any evaluative judgement at all. And you can take the experimental setup behind sports competitions seriously and see elite sport as a means of teasing out the limits of the human nature. This will be of little fun, however. It is when admiration for the winners, and the underlying evaluative judgement is added, that the nastiness surfaces and the public interest kicks in.

This is not to say, of course, that all negative evaluative judgements are nasty. If a chess-player is told that a particular move was bad, and even if it is added that this shows that the player is poor at chess, this need not be taken as any offence; this is so since here there is room for improvement. If the message is that the player should practice and learn more, then the negative evaluative stance makes good pedagogical sense and carries no trace of any implicit contempt. The problematic evaluations are when someone is considered bad in a way which is given by her (biological) nature. If it is added, in the chess example, not that the player should practice more, but that she is not only bad at chess but is too stupid by nature to be able ever to learn how to play well, then this evaluation does express contempt. This exemplifies the kind of attitude to natural weakness that was typical of Nazism.

It might be objected that it might well be the case that we all, all of the time, lack free will. ${ }^{7}$ Doesn't that mean that I rely here on a distinction without a difference? It does not. It might be true that our will is not free, and yet, for all that, it is sometimes possible for us to act otherwise than we do. I rely here on a compatibilist notion of free action where, (very) roughly speaking, I could have acted differently if, had I decided to do so, I would have done it. We are not always capable of acting differently in this sense. For example, addiction may mean that, even if I had made a different decision, I would have done what I did. This may be true of some who dope in sport contexts. Their decision to abstain, had they made one, would not have been effective. But, according to this compatibilist notion of free action, we can in many situations act differently from how we do act. We have no choice regarding our genetic setup, or more generally regarding our congenital physical and mental abilities, however ${ }^{8}$. Hence, we deserve neither praise nor blame for having them.

\section{Egalitarianism and the Future of Sport}

All this raises the question: is it possible for sport authorities to uphold this notion of justice when outside the world of sport ordinary people enhance their capacities relevant for sport? My conjecture is that successively this notion of justice in sport will come under ever more severe pressure. The sports authorities will be squeezed from two directions: people at large will come to use methods artificially enhancing their capacities, and it will in many cases be impossible to test for the use of these methods. Neuro-doping exemplifies both these tendencies. The adoption of double standards prohibiting only what is not used by the public at large and what is possible to detect - will be resorted to at first, but, when the pressure is high enough, this practice will eventually have to go.

\footnotetext{
${ }^{7}$ I thank an anonymous reviewer for pressing this point.

${ }^{8}$ See [9] for a defense of this analysis.
} 
The following example is illustrative. There exist today alternative ways of achieving superior endurance in sport. I think of hemoglobin levels in blood. A few (rare) people have a genetic disposition (a certain allele) rendering it possible for them easily to gain high levels of hemoglobin in their blood, and hence they have a natural advantage over other people. In the $1960 \mathrm{~s}$, Eero Mäntyranta was probably the best endurance athlete in the world. He was a cross-country skier and winner of seven Olympic medals, three of them gold. In the 15-km race at the 1964 Winter Olympics he won by a margin that's never been equaled. Twenty years after Mäntyranta retired, a group of scientists found him to have a rare gene mutation that runs in his family, making the carriers over-responsive to their own Erythropoietin (EPO), the hormone that cues the body to produce red blood cells.

You are allowed by sports authorities to compete even if you carry this allele. It is also allowed by sports authorities for those who lag behind to catch up through certain methods, such as training at high altitude or in oxygen tents. I suppose this is so because it is difficult to detect if such training procedures take place and it would be difficult to know what to say about people who happen to live at high altitudes. It is prohibited though, to achieve the same levels through blood doping or the use of medication such as EPO. These methods are thought to be 'artificial'. When an athlete is found to have high levels of oxygen it is often difficult to ascertain if the means used to the same effect has been permitted or prohibited ones, however. This puts sport under pressure.

And there are other examples such as caffeine, which has a documented enhancement effect and which was once on the forbidden list, but which has since been taken off the list only because it is so widely spread in society at large. And yet, the scientific evidence supporting the claim that caffeine has an enhancing effect is stronger today than it was when it was still kept on the prohibited list. ${ }^{9}$

It bodes ill for the WADA ideology that the authority has not been able to put either caffeine or neuro-doping on the prohibited list. There is certainly more to come in the future.

We sometimes learn that it is out of concern for the athlete's health that substances such as EPO are

\footnotetext{
${ }^{9}$ For a recent review of the matter see [10]
}

prohibited. This is 'bullshit', in the strict sense defined by Harry Frankfurt as speech intended to persuade without regard for truth [11]. If health would be an issue, certain maximum levels of oxygen could be stipulated, without any regard to how they had been achieved. For a while such limits were stipulated, but the second step was never taken: to allow any means to achieve the desired level.

It should also be kept in mind that there are sports where it is possible to win a fight by killing your adversary (for example in boxing).

Finally, the health argument has been definitely undermined by the positive requirement made by WADA on Castor Semenya that, unless she dopes (down), she is not allowed to compete.

When certain methods are prohibited, then, this comes at most in addition to a concern for health. What is really troubling, from the point of view of sports authorities, keeping an eye at the ethos of sport, is different. The idea is that those who are naturally strong should excel and defeat those who are naturally weak. For a weak person to catch up through artificial means, means cheating. Contrary to what has sometimes been claimed, my impression is that the perfect sport hero is one who excels and defeats everyone else without effort. Remember again Odysseus. Note that while excellence in performance is stressed, there is no mention of hard work or effort in WADA's characterization of the spirit of sport. The individual who is naturally superior should excel in the competition.

Neuro-doping put to use together with genetic engineering and other possible means will lead to a situation, then, where we level out our natural differences between people in general (outside sport). Will elitist sport survive when this has happened?

There comes a day where most people have acquired the skills that are today characteristic of only a few naturally talented people who excel in their respective sports. It is not only that we drink coffee, move around (train), and do similar trifle things, but with a high probability we will also in the future resort to neurodoping, genetic engineering and other potent enhancement methods. Then eventually sport authorities will have to yield to reality. It would be ridiculous if top athletes, relying on their natural talents, could be defeated by ordinary folks, having taken advantage of enhancement techniques. No one would be willing to pay in order to watch these wimpy athletes compete with one another. 
The question we must ask, then, is what effect this will have on elite sport itself. Everyone will be allowed to compete, and everyone will now compete with roughly the same capacities for the sport in question. Every skier will be like Mäntyranta. Or, to put it more realistically, since not all people would like to compete in sport: those who want to compete in sport will have a possibility to do so on equal biological terms with other people (allowing for the existence of specific classes, perhaps, defined in sex-neutral terms of length, height, muscle mass, testosterone levels, and so forth).

Suppose sport authorities will find that all safe methods of enhancement, regardless of how artificial they may seem, should be accepted within sport. There will be no ban on neuro-doping or similar future techniques. This will destroy what is today considered as the core of the ethos of sport. The fascination with natural strength has to go. Will elitist sport survive such a change? Will it render elitist sport irrelevant to people at large? Will there be any more money to be earnt from arranging top level sport events — or taking part in them?

Two main alternative possible futures seem to be worthy of consideration.

One possibility is that there will still be much interest in top level competitions. The outcome will now be unpredictable. No one excels because of superior natural talent. Instead there is plenty of room for what the sport philosopher Warren Fraleigh has called the sweet tension of uncertainty of outcome.

Today there exists a romantic yearning to this effect. Sports competitions become more and more arranged like scientific experiments. There shall be no room for randomness. The individual that is by nature most talented, and who has had the natural capacity to endure the most and the hardest training, is the one who is supposed to win. And we in the audience are supposed to cheer for this Übermensch. However, some people seem to feel that we have moved too far in this scientististic direction. They object to the use of VAR (the Video Assisted Referee) in football, for example, and yearn for a situation more like the one where a team could win because of sheer luck. A violation of the rules of the game went unnoticed, or the team happened to have the wind on their side at the crucial moment, for example. Some sport commentators glorify this lost golden age. Now, suppose we get there once again, i.e. into a situation where chance plays a crucial role for the outcome of sports competitions. On this scenario, there will be little interest in who is winning a competition. Instead the main focus would be on the aesthetic qualities exhibited in the performance by the athletes. Could such an interest in aesthetic qualities, and in the random character of the outcome of the competition, sustain elitist sport? Can it attract necessary sponsorship? Can it attract enough interest from the public at large? Can it engage athletes? It is hard to tell, but it is difficult to believe that much money will now go into the business.

Another scenario is more likely. We admire the winners in top-athletic sports because they are, and are perceived by us to be, superior beings with outstanding natural talents. We like to see the best specimen of the human race prevail. We want to cheer for them. And we are always in the search of a new even more highly talented creature. We are interested in particular of those who stand out. We want to see a Jesse Owens, a Carl Lewis, or a Usain Bolt win a $100-\mathrm{m}$ dash. We are prepared to stay up in the night in order to follow their careers. Since these highly and naturally skilled people are rare, we can learn them by name and personality and character; they can take a place also in popular culture, they can become famous for being famous. When all this is gone so is our interest in the business.

I must admit that this is what I hope will happen in the future. I hope a program of biological egalitarianism, which I think is morally obligatory and likely to be implemented in at least all well-ordered welfare states, will put an end the elitist sport as we now know it.

\section{Conclusion}

It would be better if we could get rid entirely of these sentiments connected to natural strength and weakness typical of elitist sport, not only in sport where they are openly cherished, but in society in general. It is true that some make their Tinder choice based on natural beauty exhibited by the one who offers contact, and even in cultural and scientific contexts we arrange with competitions where those who are most naturally talented are supposed to gain the upper hand. However, in all these fields what we do seems to me to be the result of a perverted morality which we had better, to the extent that we can, get rid of. In our choice of partner, we had better go for character and interests than superficial looks, and in science and art, what we should admire 
are the results of achievements, not the scientists' and artists' congenital skills. To the extent this is possible, we should distance ourselves from the fascination with natural strength (and beauty). And it is likely that a program of biological egalitarianism, effectively implemented, could help us a long way towards this end. The more our relative successes depend on other things than our congenital and natural 'strength', such as devotion or chance, the less tempted we will be to glorify congenital and natural strength.

A reform of sport flowing from biological equality would not destroy sport entirely, but it would leave it where is should be: as an activity we can all engage in to the extent, but only to the extent, that we enjoy it. Moreover, if we engage on equal biological terms in sport, we can do so not mainly for the sake of any audience but for the sheer fun of being part of a thrilling event, hopefully filled with aesthetic moments, and with an unpredictable outcome.

Funding Information Open access funding provided by Stockholm University.

Open Access This article is licensed under a Creative Commons Attribution 4.0 International License, which permits use, sharing, adaptation, distribution and reproduction in any medium or format, as long as you give appropriate credit to the original author(s) and the source, provide a link to the Creative Commons licence, and indicate if changes were made. The images or other third party material in this article are included in the article's Creative Commons licence, unless indicated otherwise in a credit line to the material. If material is not included in the article's Creative Commons licence and your intended use is not permitted by statutory regulation or exceeds the permitted use, you will need to obtain permission directly from the copyright holder. To view a copy of this licence, visit http://creativecommons.org/licenses/by/4.0/.

\section{References}

1. Gazerani, Parisa. 2017. Performance Enhancement by Brain Stimulation. Journal of Sports Science \& Medicine 16: 438439.

2. Pugh, J., and C. Pugh. 2020. Neurostimulation, doping, and the spirit of sport. Neuroethics. https://doi.org/10.1007 /s12152-020-09435-7.

3. Buchanan, Allen, Dan W. Brock, Norman Daniels, and Daniel Wikler. 2000. From Chance to Choice. Cambridge: Cambridge University Press. p. 152.

4. Torbjörn Tännsjö, 'Biological Egalitarianism' in Mads Rosendahl Thomsen, Jacob Warming and Kasper LippertRasmussen (eds.) The Post-Human Condition (Aarhus: Aarhus University Press, 2012).

5. Tännsjö, Torbjörn. 2009. Ought We to Enhance Our Cognitive Capacities? Bioethics 23 (7): 421-432.

6. Tännsjö, Torbjörn. 1998. Is Our Admiration For Sports Heroes Fascistoid? Journal of the Philosophy of Sport, $X X V: 23-34$.

7. Ofstad, Harald. 1989. Our Contempt for Weakness: Nazi Norms and Values - And Our Own. Stockholm: Almqvist \& Wiksell International.

8. Tännsjö, Torbjörn. 2015. A realist and internalist response to one of Mackie's arguments from queerness. Philosophical Studies 172: 347-357.

9. Svedberg, Maria, and Torbjörn Tännsjö. 2017. Consequentialism and Free Will: The Conditional Analysis Resuscitated. The Harvard Review of Philosophy 24: $23-41$.

10. Jozo Gricic et al. 2018. 'Wake up and smell the coffee: caffeine supplementation and exercise performance - an umbrella review of 21 published meta-analyses, British Journal of Sports Medicine, https://bjsm.bmj. com/content/early/2019/03/29/bjsports-2018-100278

11. Harry Frankfurt, On Bullshit (Princeton University Press, 2005).

Publisher's Note Springer Nature remains neutral with regard to jurisdictional claims in published maps and institutional affiliations. 